\title{
Magnetic resonance hypointensive signal primarily originates from extracellular iron particles in the long-term tracking of mesenchymal stem cells transplanted in the infarcted myocardium
}

\author{
This article was published in the following Dove Press journal: \\ International Journal of Nanomedicine \\ 2 March 2015 \\ Number of times this article has been viewed
}

Zheyong Huangl,*
Chenguang $\mathrm{Li}^{1, *}$
Shan Yang
Jianfeng Xu'
Yunli Shen
Xinxing Xie
Yuxiang Dai'
Hao Lu'
Hui Gong
Aijun Sun'
Juying Qian'
Junbo Ge'

'Shanghai Institute of Cardiovascular Diseases, Zhongshan Hospital, Fudan University, Shanghai, People's Republic of China; ${ }^{2}$ Department of Radiology, Zhongshan Hospital, Fudan University, Shanghai, People's Republic of China; ${ }^{3}$ Department of Cardiology, Shanghai East Hospital, Tongji University, Shanghai, People's Republic of China; ${ }^{4}$ Department of Cardiology, Qianfoshan Hospital, Shandong University, Jinan, Shandong Province, People's Republic of China; ${ }^{5}$ Institute of Biomedical Science, Fudan University, Shanghai, People's Republic of China

*These authors contributed equally to this work

Correspondence: Junbo $\mathrm{Ge}$ Shanghai Institute of Cardiovascular Diseases, Zhongshan Hospital, Fudan University, I80 Feng Lin Road, Shanghai 200032, People's Republic of China

$\mathrm{Tel}+862164041990$ ext 2153

Fax +86 2I 64223006

Email junboge@।26.com
Purpose: The long-lasting hypointensities in cardiac magnetic resonance (CMR) were believed to originate from superparamagnetic iron oxide (SPIO)-engulfed macrophages during long-term stem cell tracking. However, the iron clearance capacity of the ischemic heart was limited. Therefore, we speculated that the extracellular SPIO particles may also be involved in the generation of false-positive signals.

Methods and results: Male swine mesenchymal stem cells (MSCs) were incubated with SPIO for 24 hours, and SPIO labeling had no significant effects on either cell viability or differentiation. In vitro studies showed that magnetic resonance failed to distinguish SPIO from living SPIO-MSCs or dead SPIO-MSCs. Two hours after the establishment of the female swine acute myocardial infarction model, $2 \times 10^{7}$ male SPIO-labeled MSCs $(n=5)$ or unlabeled MSCs $(n=5)$ were transextracardially injected into the infarcted myocardium at ten distinct sites. In vivo CMR with $\mathrm{T} 2$ star weighted imaging-flash-2D sequence revealed a signal void corresponding to the initial SPIO-MSC injection sites. At 6 months after transplantation, CMR identified $32(64 \%)$ of the 50 injection sites, where massive Prussian blue-positive iron deposits were detected by pathological examination. However, iron particles were predominantly distributed in the extracellular space, and a minority was distributed within $\mathrm{CD}_{68}$-positive macrophages and other $\mathrm{CD}_{68}$-negative cells. No sex-determining region Y DNA of donor MSCs was detected. Conclusion: CMR hypointensive signal is primarily caused by extracellular iron particles in the long-term tracking of transplanted MSCs after myocardial infarction. Consideration should be given to both the false-positive signal and the potential cardiac toxicity of long-standing iron deposits in the heart.

Keywords: superparamagnetic iron oxide nanoparticles, SPIO, cardiac magnetic resonance (CMR), stem cells tracking, extracellular iron particles, myocardial infarction (MI)

\section{Introduction}

Cell transplantation has been considered a promising therapeutic strategy for acute myocardial infarction (MI). However, clinical trials using adult mesenchymal stem cells (MSCs) and other bone marrow-derived cells have indicated that the initial global benefits observed in cardiac function might be slight and transient, ${ }^{1,2}$ which is partly attributable to the low cell survival and engraftment observed after myocardial delivery. ${ }^{3,4}$ To address this issue, a non-invasive and in vivo method for tracking cell fate and quantifying cell survival after transplantation needs to be applied. ${ }^{5}$

Monitoring of stem cells using magnetic resonance imaging (MRI) is based on the imaging of superparamagnetic iron oxide (SPIO) nanoparticles, which causes magnetic 
field perturbations that can be identified on T2-weighted images..$^{5}$ Over the past 10 years, many preclinical studies and clinical trials have used SPIO and cardiac magnetic resonance (CMR) imaging to deliver, track, or determine the efficacy of stem cell therapy in the heart. ${ }^{6-14}$ The detected signal is used to estimate the number of cells. Even recently, SPIO was still used to label and assess the long-term (2 months) survival of human-induced pluripotent stem cellderived cardiomyocytes in infarcted myocardia of mini-pigs. ${ }^{15}$ However, the ability of iron oxide nanoparticles to reliably evaluate long-term stem cell engraftment in the heart has been increasingly suspected. SPIO may not stay inside the transplanted cells over time, but it may be phagocytized by macrophages. Terrovitis et al were the first to report that CMR and ferumoxide cell labeling did not provide reliable information on long-term cell viability and might overestimate ferumoxide-labeled stem cell survival after transplantation. ${ }^{16}$ Other studies have also reported that longlasting CMR hypointensities arose from cardiac macrophages that engulfed the SPIO nanoparticles. ${ }^{17-19}$

Conversely, the heart is not a monocyte-macrophage organ, and it has been demonstrated that myocardial iron is cleared more slowly in the heart than in the liver. ${ }^{20}$ It is difficult for macrophages to move all of the massive SPIO introduced by SPIO-labeled stem cells in the ischemic or necrotic region because of the lack of blood flow and mechanical contraction. Therefore, we speculated the extracellular iron particles may persist in the myocardial interstitial space and may be involved in the generation of hypointensive magnetic resonance (MR) signals in longterm cell tracking.

We conducted this study to explore the composition of the material that produces hypointensities in CMR, and more specifically, to clarify the role of extracellular iron particles in the long-term tracking of SPIO-labeled MSCs in a swine model of MI.

\section{Materials and methods}

\section{Cell preparation and labeling}

MSCs were isolated from male swine (from the Shanghai Animal Administration Center) and cultured at $37^{\circ} \mathrm{C}$ in a $5 \% \mathrm{CO}_{2}$ incubator, as previously described. ${ }^{21,22}$ Dulbecco's Modified Eagle's Medium (DMEM) (Thermo Fisher Scientific, Waltham, MA, USA) with 10\% fetal bovine serum (FBS) (Thermo Fisher Scientific) and penicillin-streptomycin (Thermo Fisher Scientific) was used as a standard culture medium. All cells used in this study were of second to third passage with a confluency of $80 \%-90 \%$.
To label the MSCs, we used an injectable solution of ferumoxides, a type of SPIO ( $50 \mu \mathrm{g} \mathrm{Fe} / \mathrm{mL}$ Resovist; Schering AG, Berlin, Germany) combined with poly-L-lysine (average molecular weight [MW] $275 \mathrm{kDa}$ ) (Thermo Fisher Scientific). Resovist was added to the serum-free culture medium (final concentration: Resovist $50 \mu \mathrm{g} / \mathrm{mL}$, poly-L-lysine, $1.5 \mu \mathrm{g} / \mathrm{mL}$ ) and mixed for 60 minutes with intermittent shaking by hand; the MSCs were then incubated with this mixture for 24 hours, as described previously. ${ }^{23}$ Before injection, the medium was discarded, and the cells were washed twice with phosphatebuffered saline (PBS), treated with trypsin (Thermo Fisher Scientific), collected, rewashed, and counted to adjust the cell concentration for the transplantation.

To evaluate the labeling efficacy, Prussian blue staining (potassium ferrocyanide and $\mathrm{HCl}$ solution from Juesheng Biotechnology Co, Ltd, Shanghai, People's Republic of China) and electron microscopy (Philips CM120; Philips NV, Amsterdam, the Netherlands) were undertaken to indicate the presence and localization of intracellular iron particles. To determine the attenuation of iron content in cells over time, labeled MSCs continued to be cultured in medium, and the iron content of the cells was quantified every 4 days using atomic absorption spectrometry (Thermo E.IRIS Duo ICP; Thermo Fisher Scientific).

\section{Cellular proliferation, viability, and differentiation}

The proliferation and viability of unlabeled MSCs and SPIOlabeled MSCs were compared. In the proliferation assays, cells were seeded at $3 \times 10^{5}$ cells/flask, and the medium was changed every 3 days. At subconfluence (90\%), the cells were detached with Accutase (GE Healthcare Europe GmbH, Freiburg, Germany) and counted with a CASY ${ }^{\circledR} 2$ Analyzer $\left(\mathrm{CASY}^{\circledR} 2-\right.$ Cell Counter and Analyzer System, Model TT; Hoffman-La Roche Ltd, Basel, Switzerland). The experiments were performed in triplicate. Cellular viability under the various conditions was examined according to both the Electrical Current Exclusion (ECE) method described by Lindl et $\mathrm{al}^{24}$ and the viability standard operational procedure of the manufacturer.

To evaluate the adipogenic differentiation potential, MSCs and SPIOs-MSCs were cultured in Adipogenic inductive medium (SR811D250; Amsbio, Madrid, Spain) for 21 days (medium was changed every 3 or 4 days). ${ }^{25}$ Untreated cells were maintained in DMEM with $10 \%$ FBS. Oil droplets in differentiated adipocytes were evaluated by Oil red O staining (Sigma-Aldrich Co, St Louis, MO, USA) after 21 days. 
To determine the differentiation of myocardium-like cells, MSCs and SPIO-MSCs were cultured in culture medium with added 5-aza-2'-deoxycytidine (5-aza-C; Sigma-Aldrich Co) for 24 hours. Incubation then continued in complete medium lacking 5 -aza-C, with medium changes every 3 days. Undifferentiated MSCs and normal mature swine cardiomyocytes were used as negative and positive controls, respectively. Total RNA was extracted from cultured cells using TRIzol reagent (Thermo Fisher Scientific) according to the manufacturer's protocol. Reverse transcriptase polymerase chain reaction (RT-PCR) primers (synthesized by Shanghai Sangon Biological Engineering Technology and Service Co, Shanghai, People's Republic of China) were as follows: ${ }^{25} c \operatorname{Tn} T, 5^{\prime}$-CCA GAA GAC AGA GCG GAA AA-3' and 5'-CGG GTC TTG GAG ACT TTC TG-3'; Desmin, 5'-ATG TCC AAG CCA GAC CTC AC- $3^{\prime}$ and $5^{\prime}$-GCC TCA TCA GGG AAT CGT TA-3'; $\alpha$-cardiac actin, 5'-ATG GTG GGT ATG GGT CAG AA- $3^{\prime}$ and $5^{\prime}$-TAC ATG GCA GGG ACA TTG AA-3'; and glyceraldehyde 3-phosphate dehydrogenase (GAPDH), 5'-GGG CAT GAA CCA TGA GAA GT-3' and $5^{\prime}$-AAG CAG GGA TGA TGT TCT GG-3'. Transcriptional expressions of $c \operatorname{Tn} T$, Desmin, and $\alpha$-cardiac actin genes from the MSCs and SPIO-MSCs were determined by RT-PCR according to the manufacturer's instructions. Transcription levels were standardized to the corresponding swine GAPDH level.

\section{In vitro MR imaging of SPIO and MSCs}

To evaluate the in vitro MR imaging of SPIO and MSCs under different conditions, $5 \times 10^{5}$ unlabeled MSCs, $5 \times 10^{5}$ living SPIO-MSCs, $5 \times 10^{5}$ dead SPIO-MSCs (treated with $75 \%$ alcohol solution for 10 minutes, and confirmed by trypan blue exclusion test), and SPIO alone (iron content equivalent to $5 \times 10^{5}$ SPIO-labeled MSCs) were resuspended in $0.5 \mathrm{~mL}$ $0.3 \%$ agarose gel in an Eppendorf (EP) tube. MR imaging was performed using a 1.5-T MR scanner (CV/i; GE Healthcare Europe $\mathrm{GmbH}$ ) with a $90 \mathrm{~cm}$ field of view (FOV), three acquisitions, $4 \mathrm{~mm}$ slice thickness with no gap, and a $512 \times 512$ matrix. Imaging sequences were as follows: 1) spin echo (SE) sequence: $\mathrm{T} 1$ weighted imaging $\left(\mathrm{T}_{1} \mathrm{WI}\right)$, repetition time $(\mathrm{TR})=450 \mathrm{~ms}$, echo delay time $(\mathrm{TE})=9 \mathrm{~ms} ; 2)$ fast spin echo (FSE) sequence: $\mathrm{T} 2$ weighted imaging $\left(\mathrm{T}_{2} \mathrm{WI}\right), \mathrm{TR}=4,800$ $\mathrm{ms}, \mathrm{TE}=96 \mathrm{~ms}$; and 3) $\mathrm{T} 2$ star weighted imaging $\left(\mathrm{T}_{2} * \mathrm{WI}\right)$ flash sequence: $\mathrm{T}_{2}{ }^{*} \mathrm{WI}, \mathrm{TR}=800 \mathrm{~ms}, \mathrm{TE}=26 \mathrm{~ms}$.

The signal intensity in each EP tube was obtained. The change of signal intensity relative to the unlabeled MSCs was calculated as the following:

$$
\Delta \mathrm{SI}=\frac{\mathrm{SI}-\mathrm{SI}_{\text {(ulabeled MSCs) }}}{\mathrm{SI}_{\text {(unlabeled MSCs) }}} \times 100 \%
$$

All experiments were performed in triplicate for each set of conditions.

\section{Swine MI model}

Animal experiments were approved by the Animal Care and Use Committee of Fudan University, Shanghai, People's Republic of China and were in compliance with the Guide for the Care and Use of Laboratory Animals published by the National Research Council (US) Institute for Laboratory Animal Research. ${ }^{26}$ Twenty-two female miniature swine (8-11 months old, weighing 18.9-25.1 kg) were obtained from the Shanghai Animal Administration Center, Shanghai, People's Republic of China. The swine fasted for 6 hours and were sedated with ketamine $(15-20 \mathrm{mg} / \mathrm{kg})$, diazepam $(1.5-2 \mathrm{mg} / \mathrm{kg})$, and atropine $(50-100 \mu \mathrm{g} / \mathrm{kg})$. The anesthesia was maintained with pentobarbital sodium (0.1-0.2 $\mathrm{mg} / \mathrm{kg} / \mathrm{min}$, intravenously), during which succinylcholine $(10 \mathrm{mg} / \mathrm{kg})$ was added to ensure thorough muscular relaxation when necessary. All animals were intubated and mechanically ventilated. Subsequently, the heart was exposed through a lateral thoracotomy. Anterior MI was created by ligation of the left anterior descending artery (LAD) at two-thirds of the distance from the apex. ${ }^{27}$ The electrocardiogram (ECG) was recorded to confirm the presence of infarction. A lidocaine bolus $(2 \mathrm{mg} / \mathrm{kg}$ ) was given before coronary occlusion. Following occlusion, lidocaine was infused intravenously at a rate of $50 \mu \mathrm{g} \cdot \mathrm{kg}^{-1} \cdot \mathrm{min}^{-1}$.

\section{Cardiac MR imaging and tracking of SPIO-MSCs in vivo}

To verify the in vivo MR imaging of SPIO and MSCs under different conditions, 2 hours after the ligation of LAD, unlabeled MSCs $\left(1 \times 10^{6} / 150 \mu \mathrm{L}\right)$, living SPIO-labeled MSCs $\left(1 \times 10^{6} / 150 \mu \mathrm{L}\right)$, dead SPIO-labeled MSCs $\left(1 \times 10^{6} / 150 \mu \mathrm{L}\right.$, and SPIO $\left(150 \mu \mathrm{L}\right.$, iron content equivalent to $1 \times 10^{6}$ SPIOlabeled MSCs) were injected into the peri-infarct areas with a 27-gauge needle (Thomas Scientific, Swedesboro, NJ, USA) ( $\mathrm{n}=3$ in each group). Then, the animals were transferred for CMR imaging without following up.

To explore the value of SPIO in the long-term CMR tracking of transplanted cells, $2 \times 10^{7}$ SPIO-labeled MSCs were injected at ten injection sites (each injection $=2 \times 10^{6} / 150 \mu \mathrm{L}$ ) into the peri-infarct areas with a 27 -gauge needle (swine, $n=5$ ) 2 hours after the ligation of LAD. A further MI swine with DMEM injection served as medium controls (swine, $\mathrm{n}=5$ ). CMR was performed at 3 days, and 1, 3, and 6 months after infarction. 
To visualize SPIO-labeled MSCs, high-resolution CMR images were obtained using a 1.5-T MR scanner (CV/I; GE Healthcare Europe $\mathrm{GmbH}$ ), as previously described..$^{28}$ Twelve to 18 contiguous short-axis images were acquired, covering the entire left ventricle, by applying ECG-triggered $\mathrm{T}_{2}$ WIflash sequence. The imaging parameters were as follows: $\mathrm{TR}=122 \mathrm{~ms} ; \mathrm{TE}=12.1 \mathrm{~ms}$, flip angle $=25^{\circ} ; 512 \times 512$ matrix; 4 mm slice thickness with no gap; $32 \mathrm{kHz}$ bandwidth; $28 \mathrm{~cm}$ FOV; and three acquisitions (number of signal averaged, NSA).

\section{Histopathological analysis}

Animals were sacrificed at the end of the observation period. To identify the origin of hypointensities in CMR, a series of consecutive sections was examined by combining hematoxylin eosin (HE) staining, Prussian blue staining, and antihuman macrophage $\left(\mathrm{CD}_{68}\right)$ immunohistochemical staining. For Prussian blue staining, which indicates the presence of iron, the tissue sections were incubated for 30 minutes with $2 \%$ potassium ferrocyanide (ie, Perl reagent) in $6 \% \mathrm{HCl}$ and counterstained with nuclear fast red. The sections were examined using standard immunohistochemical techniques with $\mathrm{CD}_{68}$ monoclonal antibody (Clone No PM-1K Gentaur, http:// www.gentaur.com) and a DAB kit (Juesheng Biotechnology $\mathrm{Co}, \mathrm{Ltd}) . \mathrm{CD}_{68}$ positive cells appeared with brown staining.

\section{RT-PCR of SRY DNA}

To identify the survival of transplanted male MSCs 6 months after cell transplantation, RT-PCR analysis for the swine $S R Y$ gene was conducted on DNA from infarcted hearts of female recipients treated with either MSCs from donor males or media. Genomic DNA was isolated using a Genomic DNA Isolation Kit (Qiagen NV, Venlo, the Netherlands). RT-PCR was conducted, as described previously ${ }^{29}$ using an ABI Prism 7700 sequence detection system (Thermo Fisher Scientific). Standard curves were generated by serially diluting male swine genomic DNA prepared from male MSCs. The sequence of the PCR primers used for detection of swine male-specific $S R Y$ gene was as follows: 5'-AAA GCG GAC GAT TAC AGC-3' and 5'-TTT GCA TTT GAG GGT TCT-3'. RT-PCR protocol consisted of an initial step at $94^{\circ} \mathrm{C}$ for 2 minutes, followed by 38 cycles of the following: denaturation at $94^{\circ} \mathrm{C}$ for 30 seconds, annealing at $50^{\circ} \mathrm{C}$ for 30 seconds, and elongation at $72^{\circ} \mathrm{C}$ for 30 seconds.

\section{Statistical analysis}

Descriptive variables were presented as the mean \pm standard deviation (SD). Comparisons between two groups were conducted using the unpaired Student's $t$-test. Comparisons among more than two groups were determined by a one-way analysis of variance (ANOVA) test and Bonferroni post hoc test. All statistical analyses were performed using the SPSS system (SPSS for Windows 15.0; SPSS Inc, Chicago, IL, USA). Values of $P<0.05$ were considered statistically significant.

\section{Results}

\section{Iron labeling and release rate}

SPIO-labeled MSCs showed abundant intracytoplasmic blue inclusions following Prussian blue staining, and the labeling efficiency was nearly $100 \%$. Although the cells had been washed by PBS several times before Prussian blue staining, a small amount of extracellular blue particles remained attached to the surface of cells. Transmission electron microscopy of labeled cells indicated the presence of the anionic magnetic nanoparticles exclusively in polydisperse vesicles in the cytoplasm (Figure 1).

The intracellular mean iron load $(23.77 \pm 6.06 \mathrm{pg} / \mathrm{cell})$ at day 0 decreased with the duration of culturing after magnetic labeling and was comparable with that of the nonlabeled MSCs at day 20 (Figure 2A, B) $(0.29 \pm 0.10 \mathrm{pg} / \mathrm{cell}$ vs $0.21 \pm 0.06 \mathrm{pg} / \mathrm{cell} ; P>0.05)$, indicating the fast rate of the physiological release process of intracellular iron particles. Such a release process of iron could be occasionally observed by electron microscopy (Figure 2C).

\section{The effects of SPIO labeling on cellular proliferation, viability, and differentiation}

The proliferation rate and viability showed no differences between unlabeled and SPIO-labeled MSCs (Figure 3A-B). To determine the adipogenic differentiation, the MSCs and SPIO-MSCs were cultured for 21 days in adipogenic media. As shown in Figure 3C, both MSCs and SPIO-MSCs differentiated into the adipogenic lineages, as evidenced by multivacuolar cells, with the secretion of neutral lipid droplets and confirmed by Oil red O staining. Following myocardial differentiation, RT-PCR showed that myocardial genes $c T n T$, Desmin, and $\alpha$-cardiac actin were all detected in both differentiated MSCs and SPIO-MSCs (Figure 3D). The expression of these myocardial genes was comparable between differentiated MSCs and differentiated SPIO-MSCs (Figure 3E). These results suggest that a low concentration of SPIO labeling did not affect the proliferation, viability, and differentiation capacity of MSCs.

\section{In vitro MR imaging of SPIO and MSCs}

Compared with unlabeled MSCs $\left(5 \times 10^{5}\right)$, living SPIO-MSCs $\left(5 \times 10^{5}\right)$, dead SPIO-MSCs $\left(5 \times 10^{5}\right)$ and SPIO alone $(0.6 \mu \mathrm{L}$ 

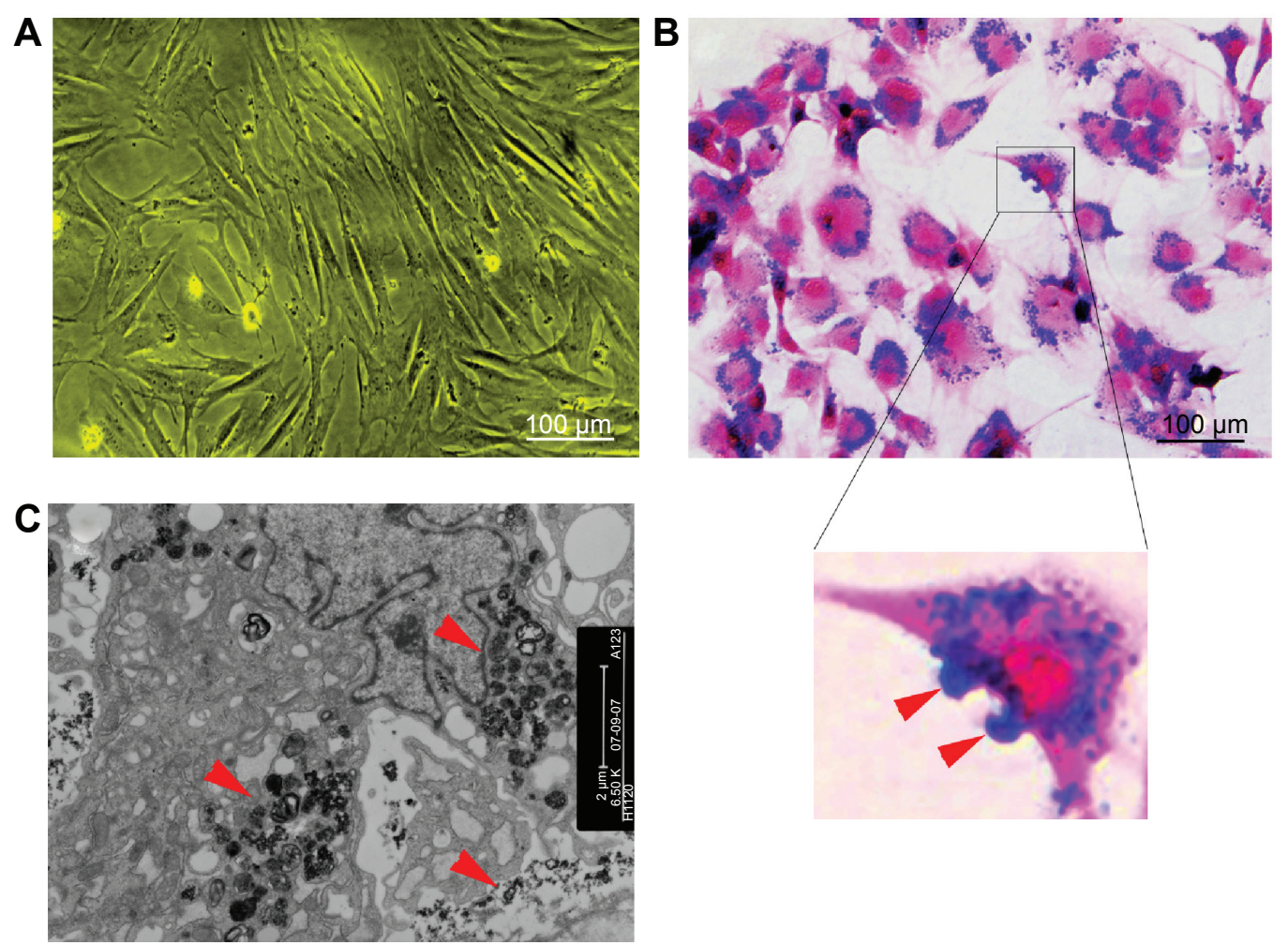

Figure I Cell labeling.

Notes: (A) Non-labeled bone marrow-derived mesenchymal stem cells in vitro $(\times 100)$. (B) Prussian blue-stained, labeled cells $(\times 100)$. The majority of blue-stained iron particles were distributed in the cytoplasm, whereas a small amount of particles adhered to the cell membrane (red arrows in inset). (C) Electron microscopic images of labeled MSCs shows dense particles (red arrows) clustered within the cytoplasm.

A

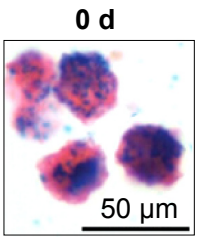

B
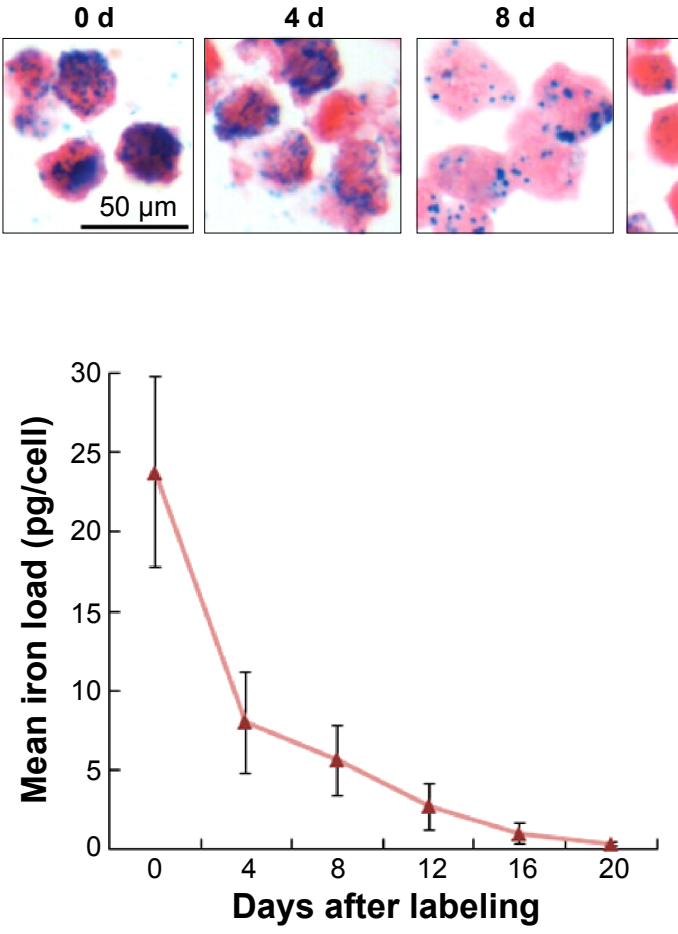

$12 \mathrm{~d}$

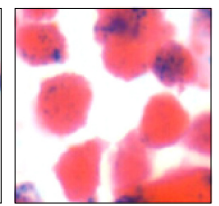

C

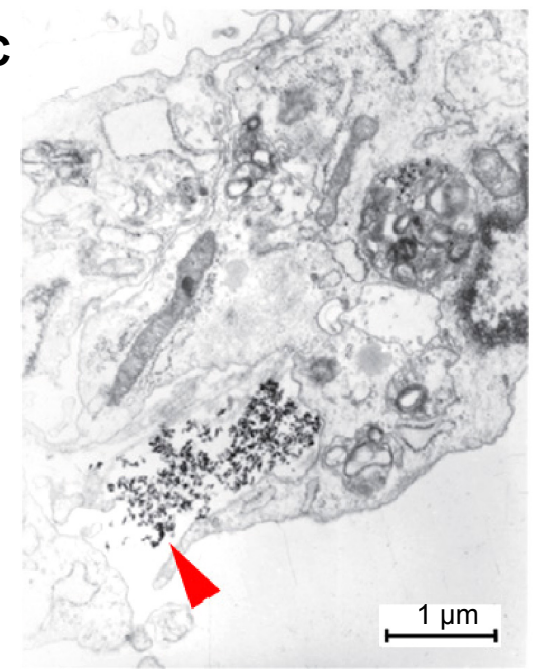

Figure 2 Release rate of intracellular iron in vitro.

Notes: (A) Prussian blue staining of SPIO-MSCs at different times after SPIO labeling (all figures in A are at $50 \mu \mathrm{m}$ in size range). (B) Quantitative analysis showing that the intracellular mean iron load decreased continuously over time after magnetic labeling. (C) Electron microscopic images of MSCs at 4 days after labeling showed the release of iron dense particles (red arrow) from the cytoplasm.

Abbreviations: d, days; SPIO, superparamagnetic iron oxide; MSCs, mesenchymal stem cells; SPIO-MSCs, mesenchymal stem cells incubated with superparamagnetic iron oxide. 
A

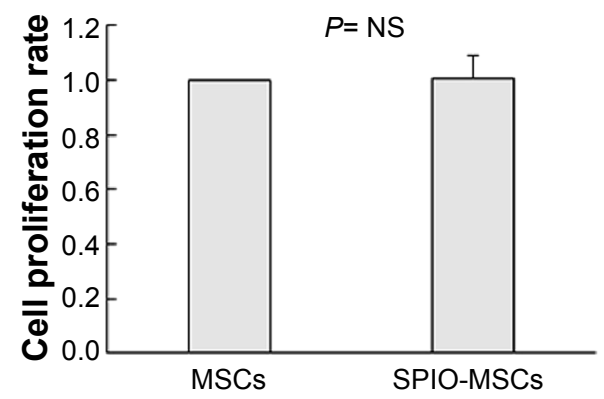

C

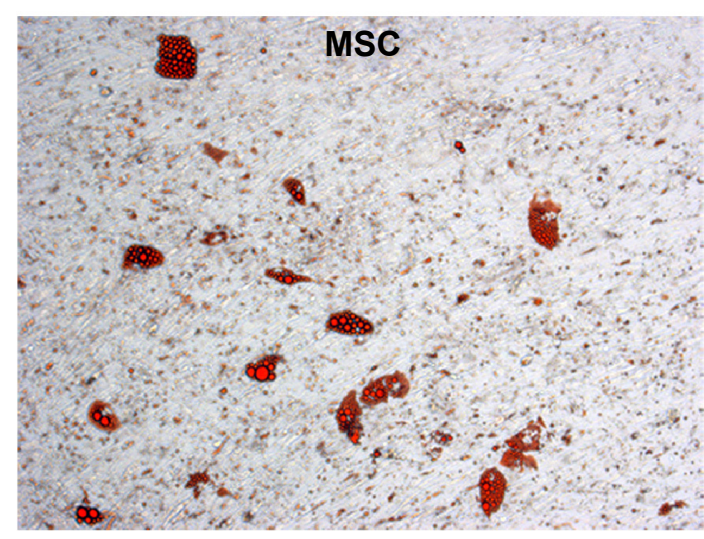

D

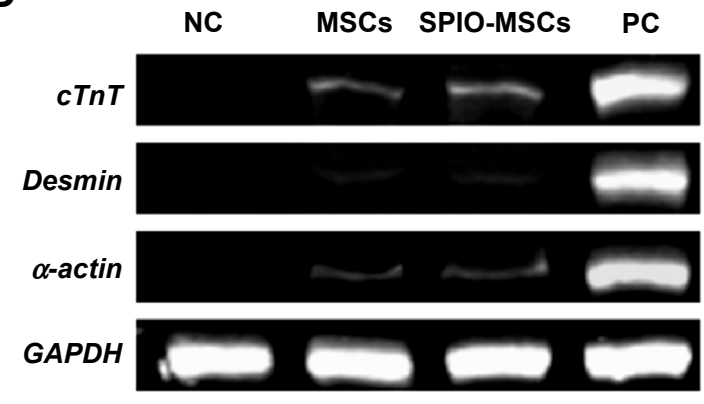

B
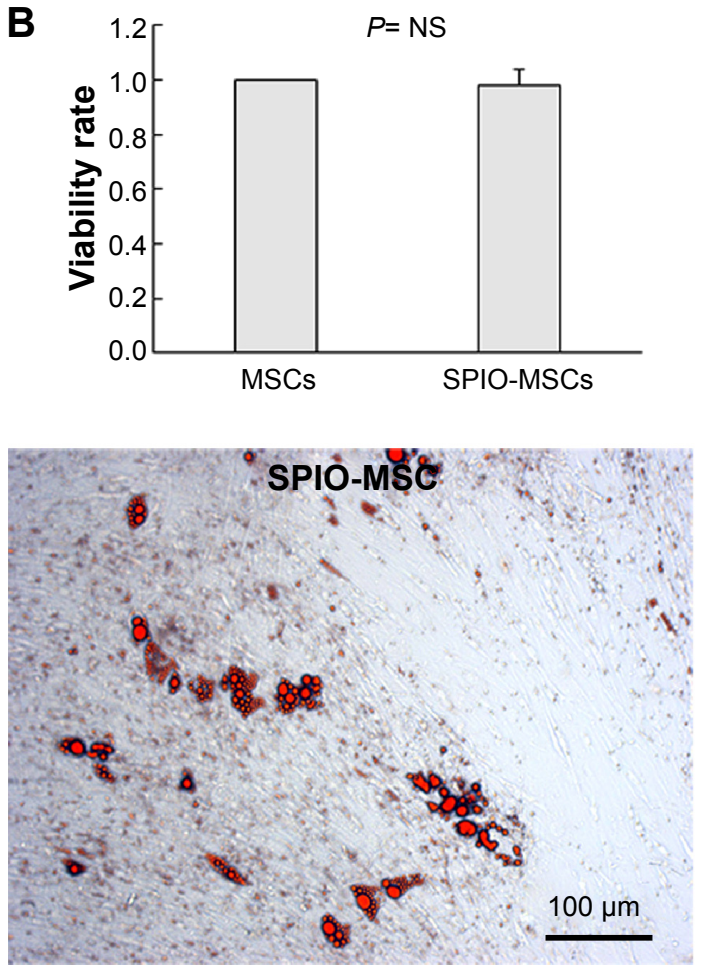

E

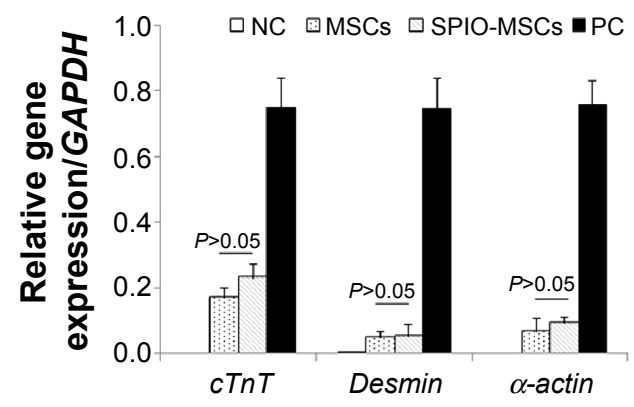

Figure 3 Proliferation, viability, and differentiation capacity of SPIO-MSCs.

Notes: (A) Proliferation rate of SPIO-MSCs. (B) Viability rate of SPIO-MSCs. (C) Oil red O staining for adipogenic differentiation (both images in C are at I00 $\mu$ m in size range). (D) RT-PCR for myocardial gene cTnT, Desmin, and $\alpha$-cardiac actin. (E) Quantitative gene expression analysis. SPIO labeling did not affect the proliferation, viability, and differentiation capacity of MSCs.

Abbreviations: MSCs, mesenchymal stem cells; SPIO, superparamagnetic iron oxide; SPIO-MSCs, mesenchymal stem cells incubated with superparamagnetic iron oxide; RTPCR, real-time quantitative polymerase chain reaction; GAPDH, glyceraldehyde 3-phosphate dehydrogenase; NS, not significant; NC, negative control; PC, positive control.

Resovist) showed similar changes in their MR signals: SE $\mathrm{T}_{1}$ WI signal increased slightly, while FSE $\mathrm{T}_{2} \mathrm{WI}$ and $\mathrm{T}_{2} * \mathrm{WI}-$ flash signal reduced obviously (Figure 4A). The change of signal intensity relative to the unlabeled $\operatorname{MSCs}(\triangle \mathrm{SI})$ showed no significant difference among the living SPIO-MSCs, the dead SPIO-MSCs, and the SPIO-alone groups (Figure 4B; all groups $P>0.05$ ), suggesting that the magnetic signal originates from SPIO itself, regardless of its location (within or outside of cells) and cell survival status (living or dead).

\section{In vivo CMR imaging of SPIO and MSCs}

In the three SPIO-containing groups (ie, the living SPIOMSCs group, the dead SPIO-MSCs group, and the SPIO alone group), CMR imaging with a $\mathrm{T}_{2} \mathrm{WI}$-flash sequence showed the same signal void (dark region) corresponding to the initial injection sites in the myocardium. However, signal-void lesions were not detected at the injection sites in the unlabeled MSC group (Figure 5). This result was consistent with in vitro cellular MR imaging, confirming that the magnetic imaging cannot distinguish between intracellular iron and extracellular iron, let alone between living cells and dead cells.

\section{Long-term signal tracking by CMR}

For the long-term CMR tracking of transplanted cells, CMR with $\mathrm{T}_{2}$ WI-flash sequence was performed at 3 days, and 1, 3, and 6 months after MSC injection in the peri-infarct areas. 


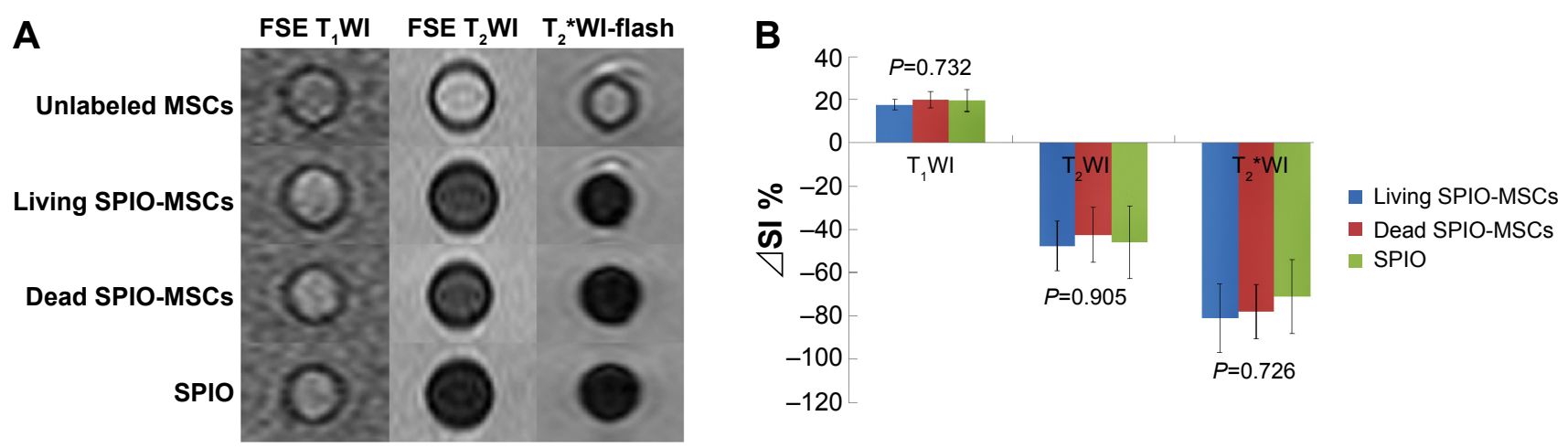

Figure 4 In vivo magnetic resonance imaging.

Notes: (A) In vivo magnetic resonance imaging of tube-containing gel with $5 \times 10^{5}$ unlabeled MSCs, living SPIO-MSCs, dead SPIO-MSCs, and SPIO alone (0.6 $\mu \mathrm{L}$ Resovist)

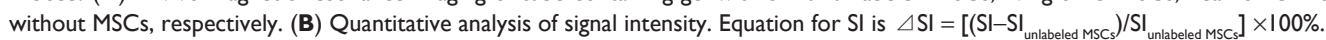

Abbreviations: MSCs, mesenchymal stem cells; SPIO, superparamagnetic iron oxide; SPIO-MSCs, mesenchymal stem cells incubated with superparamagnetic iron oxide; SI, signal intensity; FSE, fast spin echo; $T_{1} \mathrm{WI}$, TI weighted imaging; $\mathrm{T}_{2} \mathrm{WI}, \mathrm{T} 2$ weighted imaging; $\mathrm{T}_{2} * \mathrm{WI}, \mathrm{T} 2$ star weighted imaging.

The SPIO-labeled MSCs were identified as a signal void corresponding to the initial injection sites, whereas no signalvoid lesion was detected in the medium control group. In the SPIO-labeled MSCs group, 6-month serial MR images revealed that the signal-void areas gradually became less contrasted and more blurred over time (Figure 6A). However, the majority of signal-void areas could persist for a long time, as evidenced by 39 (78\%), 37 (74\%), $36(72 \%)$, and $32(64 \%)$ of the 50 sites being identified at 3 days, and 1, 3, and 6 months after transplantation, respectively (Figure 6B).

\section{Histological analysis}

Histology of swine hearts was performed at 6 months after cell injection. In contrast to the persistence of hypointensive areas
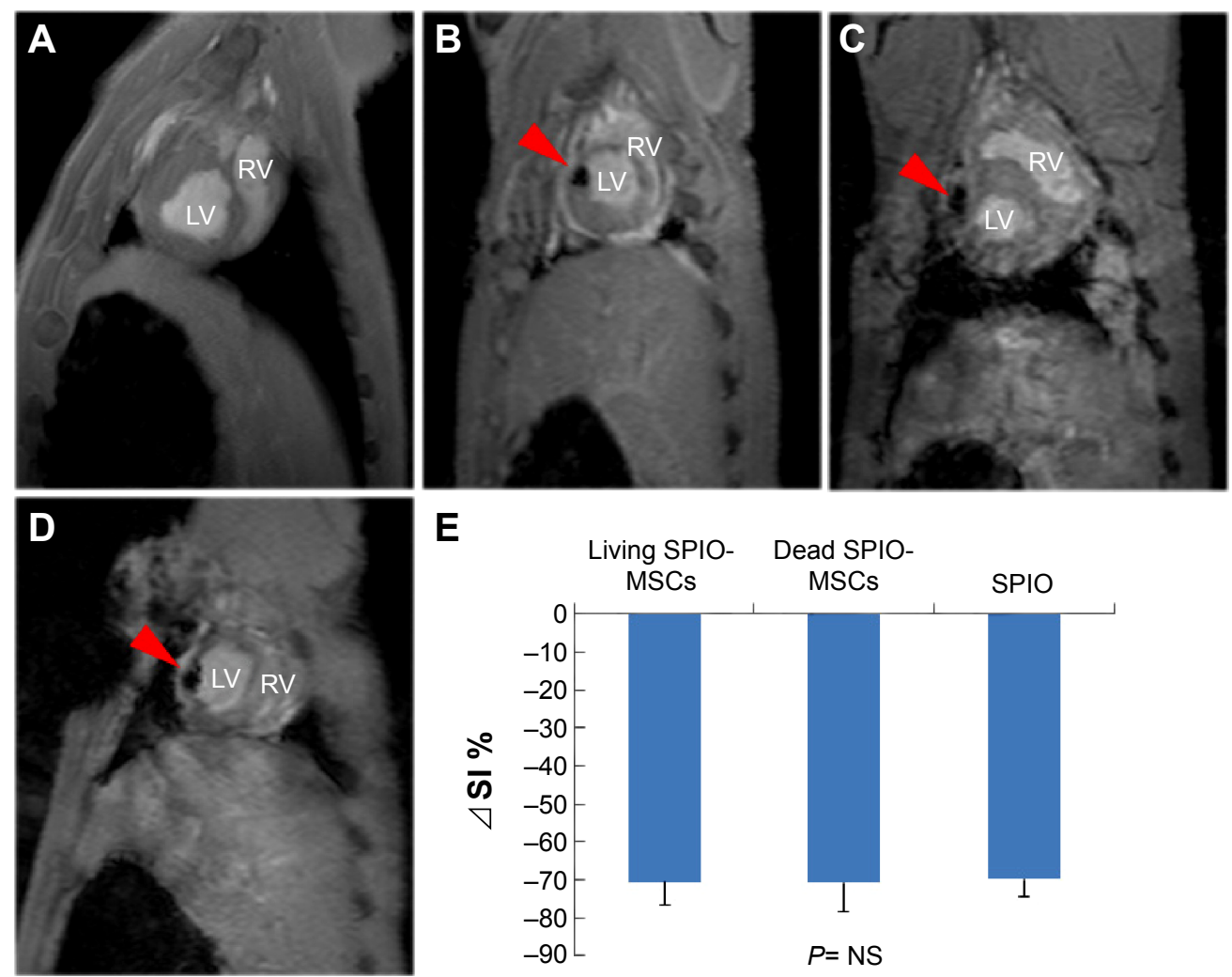

E

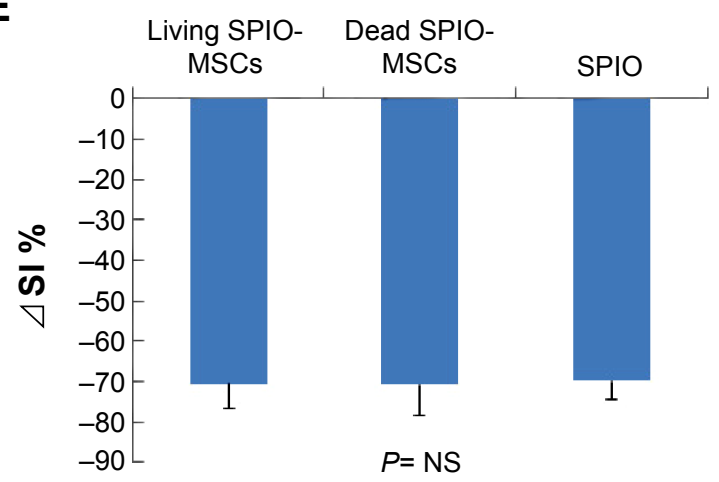

Figure 5 CMR imaging.

Notes: (A) Representative in vivo CMR imaging of injected $5 \times 10^{5}$ unlabeled MSCs, (B) living SPIO-MSCs, (C) dead SPIO-MSCs, and (D) SPIO (0.6 $\mu \mathrm{L}$ Resovist) in swine heart. Red arrows in figures B-D indicate the signal void corresponding to the injection sites. (E) Quantitative analysis of signal intensity. $\triangle \mathrm{SI}=[(\mathrm{SI}-\mathrm{Slunlabeled} \mathrm{MSCs}) / \mathrm{Slunlabeled}$ MSCs] $\times 100 \%$.

Abbreviations: CMR, cardiac magnetic resonance; LV, left ventricle; MSCs, mesenchymal stem cells; NS, not significant; RV, right ventricle; SPIO, superparamagnetic iron oxide; SPIO-MSCs, mesenchymal stem cells incubated with superparamagnetic iron oxide; SI, signal intensity. 
A

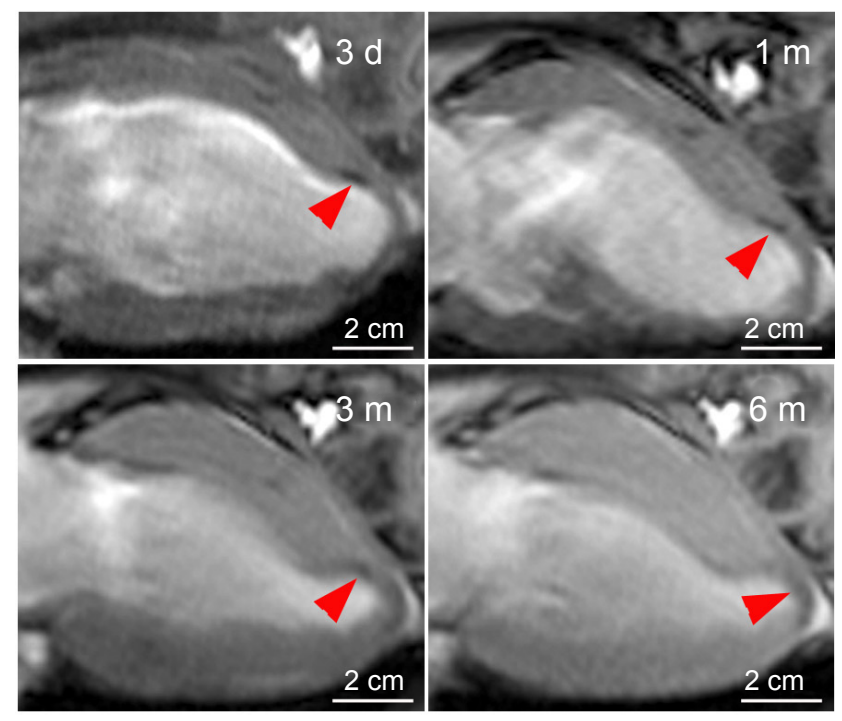

B

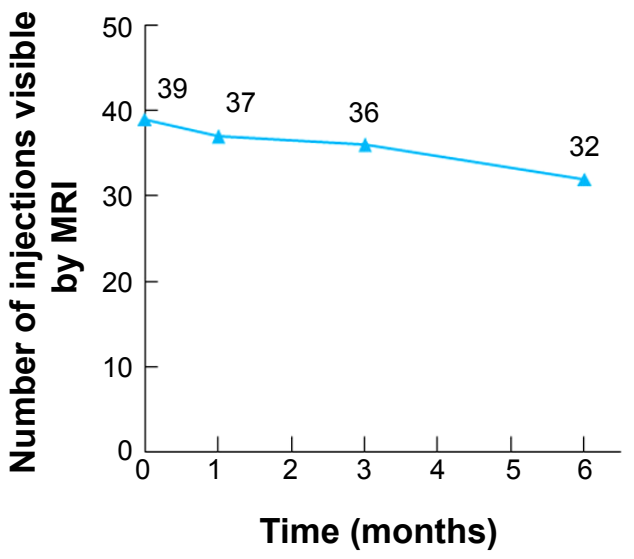

Figure 6 Long-term CMR tracking.

Notes: (A) Representative serial long-axis views imaged at $3 \mathrm{~d}, \mathrm{I}$ m, $3 \mathrm{~m}$, and $6 \mathrm{~m}$ after infarction show the signal void (red arrows) gradually faded over time. (B) The number of visible injection sites by CMR gradually decreased over time post-injection.

Abbreviations: CMR, cardiac magnetic resonance; $d$, days; $m$, months.

in CMR, no $S R Y$ sequences were detected in any of the female recipients treated with labeled MSCs, indicating that no donor MSCs survived at 6 months after cell transplantation.

On histology, massive iron (Prussian blue-positive) deposits were detected at the injection sites in tissue sections corresponding to the hypointensive signal areas in CMR. Interestingly, the deposits were almost all located in fibrous tissue, and no Prussian blue-positive deposit was observed in the normal myocardium in the peri-infarct region. The iron particles could be categorized into three groups based on the consecutive staining by HE, Prussian blue, and $\mathrm{CD}_{68}$ (a macrophage-specific antigen). First, the majority of iron particles were distributed extracellularly (red arrowhead, Figure 7A-C). Second, a certain number of $\mathrm{CD}_{68}$-positive macrophages or giant multinucleated cells were co-localized with the marginal zone of a massive iron area (Figure 7C1), indicating that macrophages engulfed a portion of the iron particles. Third, a small amount of iron particles was dispersed in the surrounding areas of massive iron accumulation. In a magnified view, some of them were distributed evenly around the nucleus, forming a spherical shell-like pattern ${ }^{23}$ and indicating an intracellular location (Figure 7B2). However, such interstitial cells that internalized iron were negative for $\mathrm{CD}_{68}$ staining.

These findings indicated that the long-lasting CMR signal primarily originated from extracellular iron particles and was only partly attributable to the intracellular iron particles. There was no relation of transplanted MSCs to the persistence of CMR hypointensities.

\section{Discussion}

Before this work, the prevalent view was that CMR of SPIO-labeled stem cells did not provide reliable information on long-term cell viability and might overestimate stem cell survival after transplantation; further, the long-lasting CMR hypointensities were believed to arise from the cardiac macrophages that engulfed the SPIO nanoparticles. ${ }^{16-19}$ Here, we found that the long-lasting CMR signal in the long-term tracking of transplanted stem cells after MI originated primarily from extracellular iron particles, rather than from intracellular iron particles.

The persistence of SPIO particles in the infarcted myocardium may be attributed to the imbalance between the massive iron release from the transplanted cells and the relatively limited iron removal capacity of the heart. Figure 8 illustrates the source and clearance of the extracellular SPIO particles. The main source of the SPIO is dead labeled cells. Due to the harsh environments, the fraction of transplanted cells that survive to later time points is typically less than $1 \%^{30}$ and may even be undetectable, as shown in this study. Even in the living stem cells, the attenuation of intracellular iron is quite rapid, as demonstrated in our in vitro study. A small amount of the SPIO attached to the surface of transplanted cells could also directly deposit in the myocardium. Additionally, MI or therapeutic intramyocardial injection may result in an iron-containing hemorrhage. The SPIO particles could be removed from the myocardium through a two-step process: first, by being engulfed by endogenous 


\section{A}

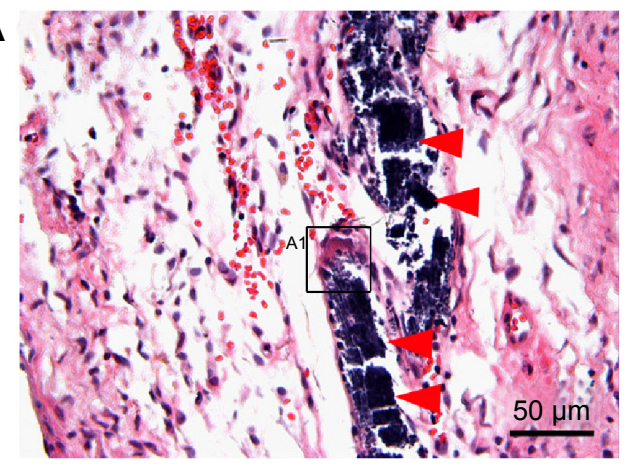

B

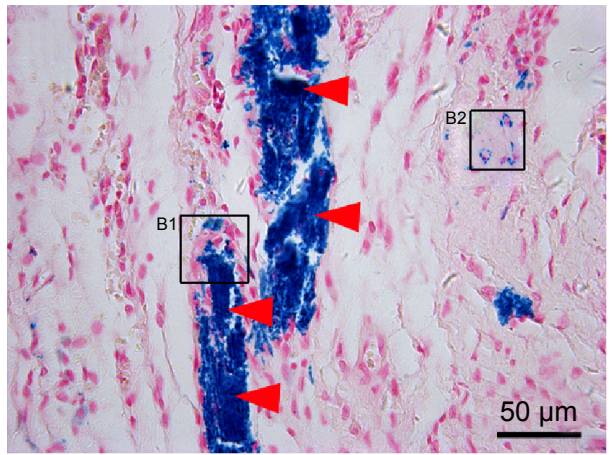

C

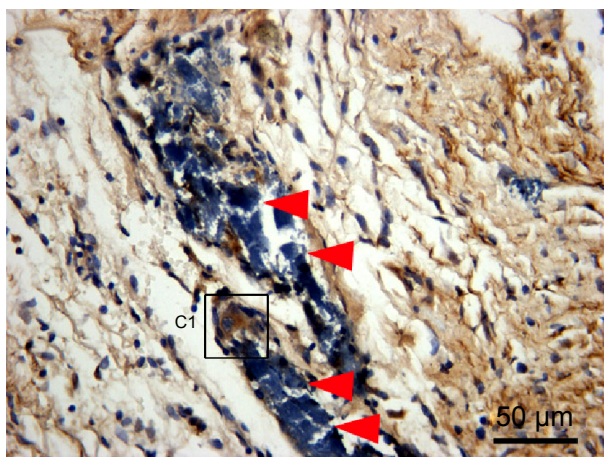

A1

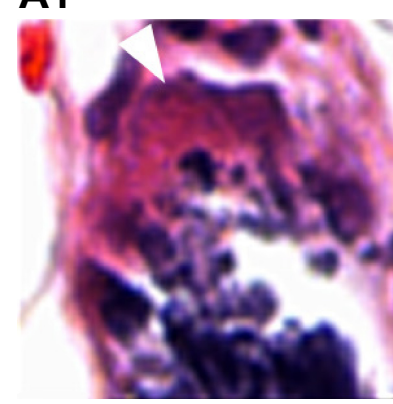

B1

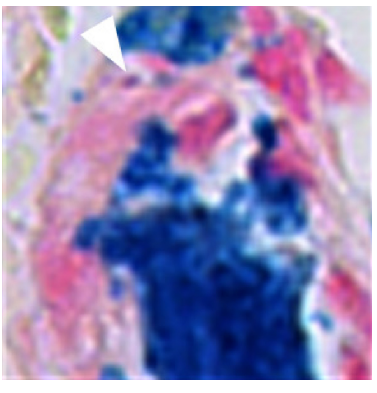

B2

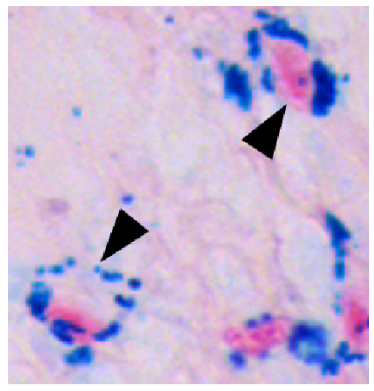

C1

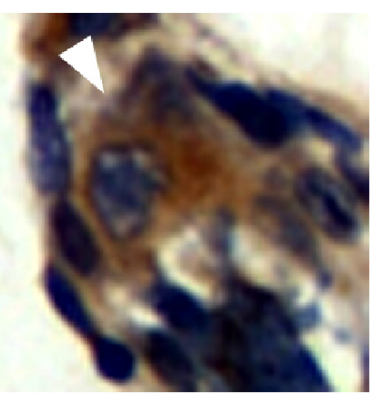

Figure 7 Representative histology of the injection sites 6 months after cell injection.

Notes: (A) HE staining. Al is the inset of $\mathbf{A}$ and shows the giant multinucleated cells. (B) Prussian blue staining. B $\mathbf{I}$ inset shows the giant multinucleated cells at the corresponding site to $\mathbf{A l}$ inset. (B2) inset shows the iron-containing, small-sized, non-macrophage interstitial cells. (C) $C_{68}$ immunohistochemical staining. $\mathbf{C l}$ inset showing the CD68-positive giant multinucleated cells at the corresponding site to Al inset and B I inset. Massive Prussian blue-positive iron deposits were detected at the injection sites. Iron particles were predominantly distributed in the extracellular space (red arrows in $\mathbf{A}-\mathbf{C}$ ), whereas a minority of iron particles were distributed within $\mathrm{CD}_{68}$-positive macrophages (white arrows in $\mathbf{A} \mathbf{I}, \mathbf{B I}$ and $\mathbf{C I}$ ) and other $\mathrm{CD}_{68}$-negative cells (black arrows in $\mathbf{B 2}$ ).

Abbreviation: $\mathrm{HE}$, hematoxylin eosin.

host cells such as macrophages, and then by being taken away by muscle contraction and coronary flow. However, the heart is quite different from the liver, spleen, and other monocyte-macrophage organs, which are rich in monocytelike or macrophage-like cells. Although circular monocytemacrophage will be attracted to and supply the scarce resident macrophages, the injected SPIO is very easily accumulated in situ ${ }^{16,20}$ because of the lack of blood flow and mechanical contraction in the ischemic or necrotic region. It is logical to assume that once the amount of SPIO or iron particles goes beyond the phagocytic capability of macrophages, the remaining SPIO will subsequently deposit in the interstitial tissue of the heart.
A possible explanation for the discrepancy in iron location between our study (extracellular) and other studies showing an intracellular location ${ }^{16-19}$ is the differences observed in the properties of the SPIO particles. It has been reported that SPIO with different sizes, coatings, and composition showed a high variation in their potential to be phagocytized by monocyte-macrophages and non-phagocytic cells. ${ }^{31-33}$ A second hypothesis is that the follow-up period in the present study was longer than those in others and that more SPIO-phagocytized cells will die in an adverse environment with more fibrotic tissues. However, the specific mechanism and process involving the iron clearance needs to be studied further, and the effect of desferrioxamine 


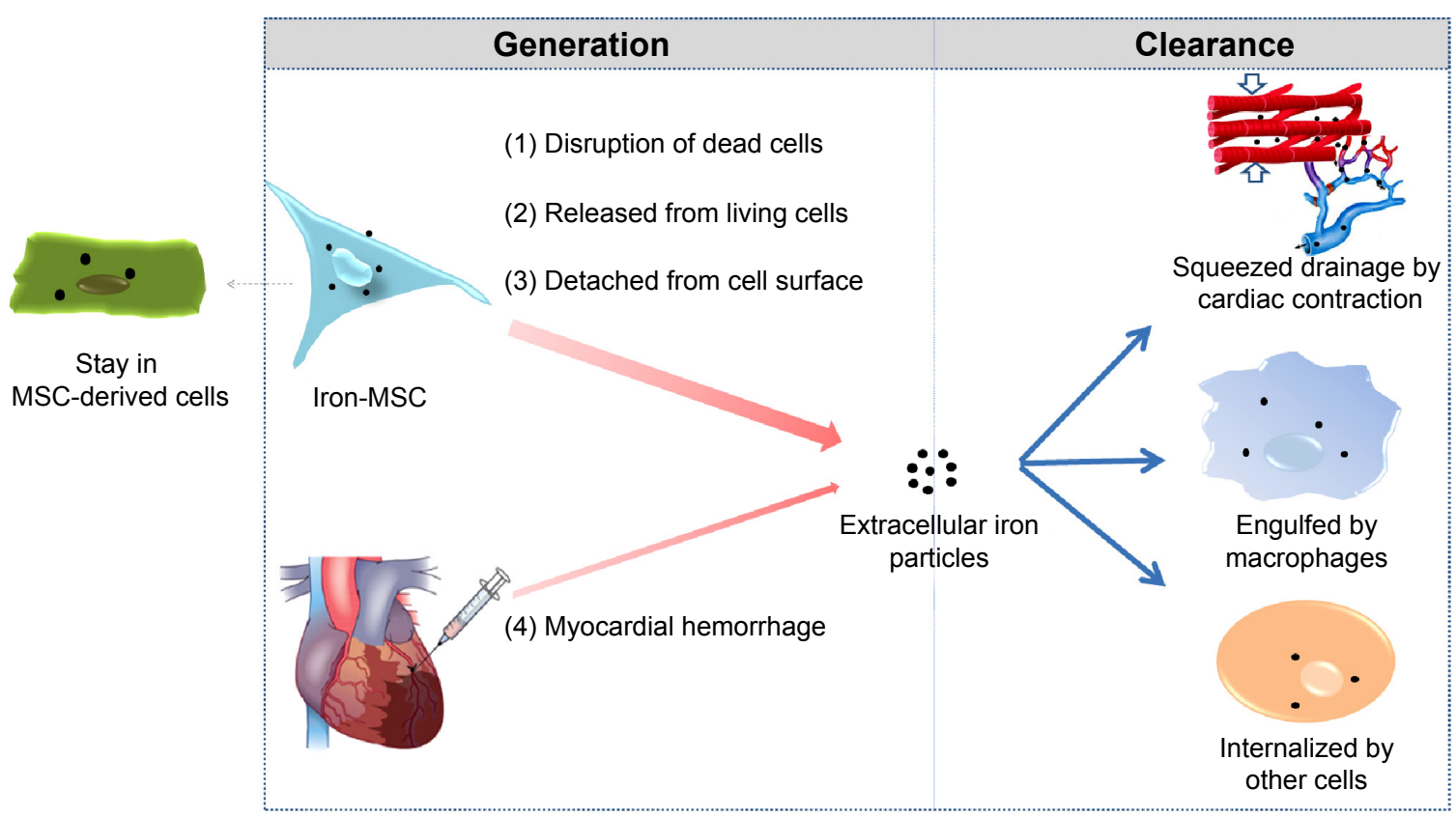

Figure 8 The source and clearance of the extracellular SPIO particles in the myocardium. Abbreviations: MSC, mesenchymal stem cell; SPIO, superparamagnetic iron oxide.

treatment in removing myocardial iron also merits further investigation.

The iron particles introduced by SPIO-MSCs were not able to be removed effectively by the heart, which may have a negative impact on long-term cell tracking. This study showed that the magnetic void signal originated primarily from iron itself, regardless of its location (within or outside of cells) and cell survival status (living or dead). Consistent with other studies, ${ }^{16-19}$ the present study confirmed that CMR of SPIO-labeled MSCs was not a reliable technique to track and quantify cells that are injected in vivo into the heart. For long-term tracking, therefore, one must be cognizant that hypointensities may overestimate the number of viable cells if free SPIO or phagocytic cells persist in the tissue. ${ }^{17}$

It is worth noting that long-standing SPIO deposition may have the potential to injure cardiac cells. Although our in vitro study showed that a low concentration of SPIO had no significant effects on MSCs' viability and differentiation, concerns should be noted about its potential cardiac toxicity for the following reasons. First, despite being coated with a polymer structure, SPIO can still be biodegraded into free iron if in the body for a long time. High levels of free ferrous iron can react with peroxides to produce free radicals, which are highly reactive and can damage cellular components. Therefore, SPIO has the potential to cause oxidative stress..$^{34-36}$

Second, the heart is considered one of the most sensitive organs to iron overload..$^{20}$ It is well known that iron overload could cause cardiomyopathy with clinical manifestations, including decreasing the cardiac ejection fraction and arrhythmia. ${ }^{37-39}$ Acidic environments prompt the transformation of iron from the oxidation state $\left(\mathrm{Fe}^{3+}\right)$ to the reduced state $\left(\mathrm{Fe}^{2+}\right)$, resulting in the generation of oxygen free radicals. Therefore, the toxic effect of myocardial iron is dynamic and is increased in the presence of metabolic acidosis. ${ }^{40}$ Based on the available data, it is logical to assume that peri-infarct ischemic myocardium, the target for SPIO-mediated stem cell therapy, is particularly susceptible to iron toxicity.

Third, when intramyocardially injected with SPIO-labeled stem cells, the local myocardium will deposit massive amounts of SPIO for a very long time, as shown in our study. The quantity and duration of SPIO deposition in the myocardium is far beyond that observed in previous intravenous studies, ${ }^{41-43}$ in which SPIO was administered systemically and proved to be a safe and efficient MR contrast agent. The situation is even worse in the context of SPIO-based magnetic targeting therapy, which was recently introduced for treating cardiovascular diseases, ${ }^{44-47}$ in which more SPIO, alongside therapeutic drugs/ cells, will be homing to the target area of the heart.

Fourth, as shown in this study, the iron particles were almost all located in fibrous tissue, and no iron deposits were observed in the normal myocardium in the peri-infarct region at 6 months after cell injection. This difference may be related to the normal removal capacity of the normal myocardium; however, it cannot be excluded that myocardial fibrosis was induced by iron toxicity. Therefore, the safety of SPIO-based cell therapy, especially the safety issues surrounding the influence of local SPIO 
particles on myocardial function, requires further investigation. Future research methodologies based on fuzzy clustering and fuzzy regression methods may also be helpful. ${ }^{48}$

Another interesting finding of this study is the presence of iron-containing, small-sized, non-macrophage cells in the myocardial interstitial tissue. Intracytoplasmic iron inclusions were distributed evenly around the nucleus of cells as a spherical shell (Figure 7B2). In view of the negative $\mathrm{CD}_{68}$ staining and no $S R Y$ gene detected, these cells seem unlikely to be MSC-differentiated cells or macrophages. Further studies are required to identify the specific cell type and its exact role in iron removal.

\section{Conclusion}

Ultimately, this study demonstrated that SPIO is of limited value in the long-term MR tracking of transplanted cells after MI and that the MR hypointensities primarily originate from extracellular iron particles. The potential toxicity of longstanding iron deposition in the heart should be considered.

\section{Acknowledgments}

The authors gratefully acknowledge financial support from the National Natural Science Foundation of China (grants 81370003, 81470467, 81000043, 81300095, and 81400318), the Natural Science Foundation of Shanghai Municipality of China (grant 15ZR1434100), and the Science and Technology Commission of Shanghai Municipality (grant 13JC1401703).

\section{Disclosure}

The authors declare no conflicts of interest in this work.

\section{References}

1. Clifford DM, Fisher SA, Brunskill SJ, et al. Stem cell treatment for acute myocardial infarction. Cochrane Database Syst Rev. 2012;2:CD006536.

2. Suncion VY, Ghersin E, Fishman JE, et al. Does transendocardial injection of mesenchymal stem cells improve myocardial function locally or globally?: An analysis from the Percutaneous Stem Cell Injection Delivery Effects on Neomyogenesis (POSEIDON) randomized trial. Circ Res. 2014;114(8):1292-1301.

3. Huu AL, Prakash S, Shum-Tim D. Cellular cardiomyoplasty: current state of the field. Regen Med. 2012;7(4):571-582.

4. Barbash IM, Chouraqui P, Baron J, et al. Systemic delivery of bone marrow-derived mesenchymal stem cells to the infarcted myocardium: feasibility, cell migration, and body distribution. Circulation. 2003;108(7):863-868.

5. Vandsburger M. Cardiac cell tracking with MRI reporter genes: welcoming a new field. Curr Cardiovasc Imaging Rep. 2014;7:9250.

6. Azene N, Fu Y, Maurer J, Kraitchman DL. Tracking of stem cells in vivo for cardiovascular applications. J Cardiovasc Magn Reson. 2014; $16(1): 7$.

7. $\mathrm{He} \mathrm{G}$, Zhang $\mathrm{H}$, Wei $\mathrm{H}$, et al. In vivo imaging of bone marrow mesenchymal stem cells transplanted into myocardium using magnetic resonance imaging: a novel method to trace the transplanted cells. Int J Cardiol. 2007; 114(1):4-10.
8. Qi CM, Ma GS, Liu NF, et al. Identification and differentiation of magnetically labeled mesenchymal stem cells in vivo in swines with myocardial infarction. Int J Cardiol. 2009;131(3):417-419.

9. Arbab AS, Bashaw LA, Miller BR, Jordan EK, Bulte JW, Frank JA. Intracytoplasmic tagging of cells with ferumoxides and transfection agent for cellular magnetic resonance imaging after cell transplantation: methods and techniques. Transplantation. 2003;76(7): $1123-1130$

10. Arbab AS, Jordan EK, Wilson LB, Yocum GT, Lewis BK, Frank JA. In vivo trafficking and targeted delivery of magnetically labeled stem cells. Hum Gene Ther. 2004;15(4):351-360.

11. Kim YJ, Huh YM, Choe KO, et al. In vivo magnetic resonance imaging of injected mesenchymal stem cells in rat myocardial infarction; simultaneous cell tracking and left ventricular function measurement. Int J Cardiovasc Imaging. 2009;25(Suppl 1):99-109.

12. Huang ZY, Ge JB, Yang S, et al. [In vivo cardiac magnetic resonance imaging of superparamagnetic iron oxides-labeled mesenchymal stem cells in swines]. Zhonghua Xin Xue Guan Bing Za Zhi. 2007;35(4): 344-349. Chinese.

13. Yang K, Xiang P, Zhang C, et al. Magnetic resonance evaluation of transplanted mesenchymal stem cells after myocardial infarction in swine. Can J Cardiol. 2011;27(6):818-825.

14. Stuckey DJ, Carr CA, Martin-Rendon E, et al. Iron particles for noninvasive monitoring of bone marrow stromal cell engraftment into, and isolation of viable engrafted donor cells from, the heart. Stem Cells. 2006;24(8):1968-1975.

15. Kawamura M, Miyagawa S, Fukushima S, et al. Enhanced survival of transplanted human induced pluripotent stem cell-derived cardiomyocytes by the combination of cell sheets with the pedicled omental flap technique in a porcine heart. Circulation. 2013;128(11 Suppl 1): S87-S94.

16. Terrovitis J, Stuber M, Youssef A, et al. Magnetic resonance imaging overestimates ferumoxide-labeled stem cell survival after transplantation in the heart. Circulation. 2008;117(12):1555-1562.

17. Amsalem Y, Mardor Y, Feinberg MS, et al. Iron-oxide labeling and outcome of transplanted mesenchymal stem cells in the infarcted myocardium. Circulation. 2007;116(11 Suppl):138-145.

18. Ebert SN, Taylor DG, Nguyen HL, et al. Noninvasive tracking of cardiac embryonic stem cells in vivo using magnetic resonance imaging techniques. Stem Cells. 2007;25(11):2936-2944.

19. Li Z, Suzuki Y, Huang M, et al. Comparison of reporter gene and iron particle labeling for tracking fate of human embryonic stem cells and differentiated endothelial cells in living subjects. Stem Cells. 2008;26(4):864-873.

20. Anderson LJ, Westwood MA, Holden S, et al. Myocardial iron clearance during reversal of siderotic cardiomyopathy with intravenous desferrioxamine: a prospective study using T2* cardiovascular magnetic resonance. Br J Haematol. 2004;127(3):348-355.

21. Amado LC, Saliaris AP, Schuleri KH, et al. Cardiac repair with intramyocardial injection of allogeneic mesenchymal stem cells after myocardial infarction. Proc Natl Acad Sci U S A. 2005;102(32):11474-11479.

22. Pittenger MF, Mackay AM, Beck SC, et al. Multilineage potential of adult human mesenchymal stem cells. Science. 1999;284(5411):143-147.

23. Huang Z, Pei N, Wang Y, et al. Deep magnetic capture of magnetically loaded cells for spatially targeted therapeutics. Biomaterials. 2010;31(8):2130-2140.

24. Lindl T, Lewandowski B, Schreyögg S, Staudte A. An evaluation of the in vitro cytotoxicities of 50 chemicals by using an electrical current exclusion method versus the neutral red uptake and MTT assays. Altern Lab Anim. 2005;33(6):591-601.

25. Kumar BM, Maeng GH, Lee YM, et al. Neurogenic and cardiomyogenic differentiation of mesenchymal stem cells isolated from minipig bone marrow. Res Vet Sci. 2012;93(2):749-757.

26. National Research Council (US) Institute for Laboratory Animal Research. Guide for the Care and Use of Laboratory Animals. Washington (DC): National Academies Press (US); 1996. 
27. Huang Z, Ge J, Sun A, et al. Ligating LAD with its whole length rather than diagonal branches as coordinates is more advisable in establishing stable myocardial infarction model of swine. Exp Anim. 2010;59(4):431-439.

28. Kraitchman DL, Heldman AW, Atalar E, et al. In vivo magnetic resonance imaging of mesenchymal stem cells in myocardial infarction. Circulation. 2003;107(18):2290-2293.

29. Zhang H, Song P, Tang Y, et al. Injection of bone marrow mesenchymal stem cells in the borderline area of infarcted myocardium: heart status and cell distribution. J Thorac Cardiovasc Surg. 2007;134(5): 1234-1240.

30. Wang PC, Shan L. Essential elements to consider for MRI cell tracking studies with iron oxide-based labeling agents. J Basic Clin Med. 2012; 1(1):1-6.

31. Thorek DL, Tsourkas A. Size, charge and concentration dependent uptake of iron oxide particles by non-phagocytic cells. Biomaterials. 2008;29(26):3583-3590.

32. Fröhlich E. The role of surface charge in cellular uptake and cytotoxicity of medical nanoparticles. Int J Nanomedicine. 2012;7:5577-5591.

33. Schlorf T, Meincke M, Kossel E, Glüer CC, Jansen O, Mentlein R. Biological properties of iron oxide nanoparticles for cellular and molecular magnetic resonance imaging. Int J Mol Sci. 2010;12(1):12-23.

34. Naqvi S, Samim M, Abdin M, et al. Concentration-dependent toxicity of iron oxide nanoparticles mediated by increased oxidative stress. Int J Nanomedicine. 2010;5:983-989.

35. Ge G, Wu H, Xiong F, et al. The cytotoxicity evaluation of magnetic iron oxide nanoparticles on human aortic endothelial cells. Nanoscale Res Lett. 2013;8(1):215.

36. Cochran DB, Wattamwar PP, Wydra R, et al. Suppressing iron oxide nanoparticle toxicity by vascular targeted antioxidant polymer nanoparticles. Biomaterials. 2013;34(37):9615-9622.

37. Gujja P, Rosing DR, Tripodi DJ, Shizukuda Y. Iron overload cardiomyopathy: better understanding of an increasing disorder. J Am Coll Cardiol. 2010;56(13):1001-1012.

38. Cokic I, Kali A, Wang X, et al. Iron deposition following chronic myocardial infarction as a substrate for cardiac electrical anomalies: initial findings in a canine model. PLoS One. 2013;8(9):e73193.
39. Kali A, Kumar A, Cokic I, et al. Chronic manifestation of postreperfusion intramyocardial hemorrhage as regional iron deposition: a cardiovascular magnetic resonance study with ex vivo validation. Circ Cardiovasc Imaging. 2013;6(2):218-228.

40. Voogd A, Sluiter W, van Eijk HG, Koster JF. Low molecular weight iron and the oxygen paradox in isolated rat hearts. J Clin Invest. 1992;90(5):2050-2055.

41. Hamm B, Staks T, Taupitz M, et al. Contrast-enhanced MR imaging of liver and spleen: first experience in humans with a new superparamagnetic iron oxide. J Magn Reson Imaging. 1994;4(5):659-668.

42. Onishi H, Murakami T, Kim T, et al. Safety of ferucarbotran in MR imaging of the liver: a pre- and postexamination questionnaire-based multicenter investigation. J Magn Reson Imaging. 2009;29(1):106-111.

43. Richards JM, Shaw CA, Lang NN, et al. In vivo mononuclear cell tracking using superparamagnetic particles of iron oxide: feasibility and safety in humans. Circ Cardiovasc Imaging. 2012;5(4):509-517.

44. Huang Z, Pei N, Shen Y, et al. A novel method to delivery stem cells to the injured heart: spatially focused magnetic targeting strategy. $J$ Cell Mol Med. 2012;16(6):1203-1205.

45. Huang Z, Shen Y, Pei N, et al. The effect of nonuniform magnetic targeting of intracoronary-delivering mesenchymal stem cells on coronary embolisation. Biomaterials. 2013;34(38):9905-9916.

46. Cheng K, Li TS, Malliaras K, Davis DR, Zhang Y, Marbán E. Magnetic targeting enhances engraftment and functional benefit of ironlabeled cardiosphere-derived cells in myocardial infarction. Circ Res. 2010;106(10):1570-1581.

47. Huang Z, Shen Y, Sun A, et al. Magnetic targeting enhances retrograde cell retention in a rat model of myocardial infarction. Stem Cell Res Ther. 2013;4(6):149.

48. Baron N, Kachenoura N, Cluzel P, et al. Comparison of various methods for quantitative evaluation of myocardial infarct volume from magnetic resonance delayed enhancement data. Int J Cardiol. 2013; 167(3):739-744.
International Journal of Nanomedicine

\section{Publish your work in this journal}

The International Journal of Nanomedicine is an international, peerreviewed journal focusing on the application of nanotechnology in diagnostics, therapeutics, and drug delivery systems throughout the biomedical field. This journal is indexed on PubMed Central, MedLine, CAS, SciSearch $®$, Current Contents ${ }^{\circledR} /$ Clinical Medicine,

\section{Dovepress}

Journal Citation Reports/Science Edition, EMBase, Scopus and the Elsevier Bibliographic databases. The manuscript management system is completely online and includes a very quick and fair peer-review system, which is all easy to use. Visit http://www.dovepress.com/ testimonials.php to read real quotes from published authors. 